\title{
Maneiras de padecer, de fruir e de (se) construir: sobre a psicodinâmica do trabalho e seu sujeito*
}

\section{Ways of suffering, feeling pleasure, and constructing (oneself): on the psychodynamics of work and its subject}

\author{
Cristiana Facchinetti \\ Psicanalista; pesquisadora do Departamento de Pesquisa e professora do Programa de Pós-graduação \\ em História das Ciências e da Saúde/Casa de Oswaldo Cruz/Fundação Oswaldo Cruz \\ cfac@coc.fiocruz.br
}

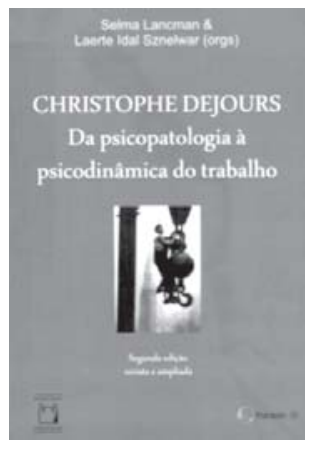

Lancman, Selma; Sznelwar, Laerte Idal (Org.). Christophe Dejours: da psicopatologia à psicodinâmica do trabalho. 2. ed. rev. ampl. Rio de Janeiro: Editora Fiocruz; Brasília: Paralelo 15, 2008. 348 p.
$\mathrm{O}$ interesse em trazer ao público uma nova edição de Christophe Dejours: da psicopatologia à psicodinâmica do trabalho, quatro anos depois de sua primeira edição, demonstra por si só que a problemática apresentada pela escola dejouriana permanece atual ainda hoje: sofrimento e prazer são categorias ainda enigmáticas no campo das organizações. Assim, a segunda edição, que possui dois textos das organizadoras e é acrescida de novos textos de Dejours acerca do conceito de psicodinâmica do trabalho, insiste na importância do sentido que o trabalho pode ter para a produção de subjetividades, já que esse dado permanece não sendo unânime para aqueles que investigam as relações do homem com seu trabalho, sejam eles advindos da academia, de organizações, sindicatos, ou mesmo dos poderes públicos (MOW, 1987).

Há trinta anos, o aumento da complexidade do mundo do trabalho e as revoluções tecnológicas puseram em questão o modelo de administração e gestão adotados desde o final da Segunda Guerra Mundial, no período de expansionismo. O modelo fordista-keynesiano passou a ser considerado por demais rígido, técnico e quantitativo e, por isso mesmo, produtor de conflitos interpessoais e profissionais em um momento de inúmeras mudanças de valores na sociedade (Harvey, 1996). Em troca, ao longo da década de 1970, novos valores se difundiram entre aqueles que "buscavam estratégias para apaziguar as relações entre capital e trabalho" (Caldas, Tonelli, Lacombe, 2002, p.63). A revolução tecnológica e as obrigações advindas do welfare state, que dificultavam a substituição dos funcionários, mais os valores humanistas que circulavam então provocaram a adoção de um modelo 'profissionalizado' de administração de pessoal (Fischer, 2002), que, se supunha, permitiria a inclusão do trabalhador por meio da análise interpessoal.

Mas a leitura dos textos dessa coletânea permite verificar que tal abordagem, que incorporou noções como motivação, liderança, comunicação e dinâmicas de grupo, apesar de passar a levar em conta o elemento humano no trabalho, manteve como objetivo primeiro a busca de maior rentabilidade e eficácia da organização. Assim, o trabalhador, se 
passara a ser considerado, o era como mera engrenagem ou recurso para atingi-las. Se isso não era tão claro em um primeiro momento, com o surgimento da 'ortodoxia' neoliberal na década de 1980, a internacionalização da economia e o esgotamento das diversas políticas econômicas, a mudança em curso sinalizou a passagem para um regime que pode ser chamado de 'acumulação flexível', consequência da forte volatilidade do mercado e do enfraquecimento do poder sindical -, em virtude da grande reserva de mão-de-obra provocada pelo desemprego ou subemprego (Navarro, 1998).

Paulatinamente, a reestruturação no campo da organização - pensada em termos de avanço e modernização, com suas avaliações individualizadas de desempenhos com suas entrevistas de avaliação, auditagens internas e externas, gestão por objetivos, balanço de competências, autocontrole e autoavaliação etc. (Zarifan, 2001) - acabou por mostrar-se repleta de inesperados efeitos adversos, como nos mostra Dejours, por exemplo, no capítulo 10. Nessa nova conjuntura sócio-histórica, houve uma escalada na competitividade no mundo do trabalho. As novas técnicas de gestão contribuíram também, de sua parte, para essa escalada conformando uma cultura organizacional de competição permanente e degradando as estratégias coletivas (Dejours, 1996).

Em consequência desse contexto, houve uma retração dos sujeitos para sua interioridade, com incremento do narcisismo, individualismo e da desestruturação das redes de solidariedade clássicas (p.19). Se operários e técnicos foram atingidos, os que se situam em cargos superiores na hierarquia também não foram poupados de grandes sofrimentos psíquicos, constituindo uma perda considerável de recursos para a saúde do trabalhador e possibilitando o crescimento das chamadas novas patologias, paradoxalmente fonte de grandes desperdícios econômicos: novas doenças psicossomáticas, mal-estar, queda de interesse e motivação, queda de rentabilidade e criatividade e, em alguns casos, até mesmo suicídio, real ou simbólico, do trabalhador foram detectados (Laurell, 1981; Hernberg, 1995; Lancman, Leal , 2008).

Foi no contexto desses conflitos e do surgimento das novas patologias que Christophe Dejours começou a pesquisar o sofrimento psíquico advindo do trabalho. Psicanalista, psiquiatra e médico do trabalho, Dejours propôs-se a investigar justamente aquilo que fora excluído das discussões: a dimensão subjetiva nas relações laborais, apoiada em uma teoria social e em uma teoria do sujeito em que o trabalho se coloca como conceito irredutível (p.31). Assim, a compreensão central que o orientou, bem como aqueles que conformaram com ele a escola dejouriana, é a de que entender a influência da organização do trabalho no psiquismo é de fundamental importância não apenas para a compreensão e intervenção de situações que possam acarretar diversas formas de sofrimento, mas também porque o campo social é o locus privilegiado de desconstrução e reconstrução da história pessoal.

Ancorado em um viés que não perde de vista a conjuntura e o contexto sócio-histórico, Dejours (por exemplo, no capítulo 8) ampliou as reflexões acerca do processo laboral, incluindo nele questões sociais prementes que vêm sendo apontadas por diversos pensadores da atualidade (Bauman, 1998; Debord, 1997). Ao indicá-las, trouxe como contribuição propostas de uma análise que se quer capaz de produzir renovações organizacionais que permitam a instauração de uma ética do trabalho, na qual o respeito e a dignidade ao trabalhador possam produzir sentido para o que faz. Na perspectiva por ele assinalada, ao 
mudar-se o trabalho pode-se mudar a vida, pode-se mudar o mundo de um sujeito e de sua coletividade.

Às dimensões física e cognitiva, Dejours incorporou a esfera psíquica por meio de recurso a saberes até então marginais para o campo da medicina do trabalho e da administração: a psicanálise, a linguística, a antropologia, a psicologia social, entre outros, trouxeram à tona novos objetos. Para além das esferas da consciência e da vontade, surgiram então investigações acerca do inconsciente, das pulsões, da alteridade, da linguagem, das relações de poder, do simbólico, do sofrimento e, last but not least, do prazer.

Crítico das abordagens neopositivistas que tradicionalmente permeiam as pesquisas acerca da saúde do trabalhador, Christophe Dejours manteve-se igualmente crítico dos saberes por ele elencados para o campo da sua própria pesquisa clínica. Assim, ao abarcar a saúde, a administração e a ergonomia, a escola dejouriana desconstruiu as fronteiras dessas disciplinas, ao introduzir no próprio cerne de seus conceitos o sujeito; por outro lado, ao focar na teoria psicanalítica, forçou o olhar para fora do imaginário e do mundo interno do sujeito, numa leitura que nos lembra que o inconsciente é constituído no 'entre' dois sujeitos; no 'entre' mundos, intra e intersubjetivo (capítulo 7). Não há sujeito sem os outros e sem a cultura que o cerca. Tampouco é possível um mundo social em que a subjetividade não se faça presente.

A publicação em 1980 de Travail: usure mentale (traduzido, no Brasil, como A loucura no trabalho, em 1987) e as intervenções de campo que desde então vêm sendo desenvolvidas pelo grupo de pesquisadores ligados ao Laboratório de Psicologia do Trabalho, sob a direção de Dejours, iluminaram de forma nova os impactos do trabalho sobre os níveis operacionais e também sobre os níveis executivos, de modo que passa a ser possível a análise do subjetivo entrelaçada à dinâmica das organizações.

Dejours tomou a centralidade do trabalho no mundo social e sua importância na contemporaneidade como um a priori, quer nas relações sujeito/sociedade, quer na própria constituição do sujeito. Inicialmente seu foco estava centrado no sofrimento, em especial aquele advindo do confronto do psiquismo com a organização de trabalho, e seu objetivo era investigar tanto as dinâmicas capazes de gerá-lo como também as estratégias individuais e coletivas que eram suscitadas por esse sofrimento. A análise que parte desse ponto de vista está desenvolvida no capítulo 1, "Addendum", especialmente nas páginas 49 a 61 .

Entretanto, como essa coletânea o demonstra, ao longo das pesquisas foi-se evidenciando que os trabalhadores não são passivos diante dos problemas organizacionais e inúmeras vezes conseguem proteger-se dos danos sobre seu psiquismo por meio de estratégias de defesa individuais e coletivas. Desviando então sua atenção para as estratégias de defesa, Dejours passou a buscar compreender como os indivíduos conseguiam manter esse equilíbrio psicodinâmico instável e precário entre o sofrimento e as defesas contra ele, sem adoecer (capítulo 5).

Foi assim que a escola dejouriana adentrou novo campo, em que foi possível propor que se o trabalho era gerador de sofrimento, uma vez que confrontaria os sujeitos com limites externos para a realização do desejo, era também passível de constituir-se fonte de prazer e ampliação do mundo subjetivo. Assim, ao longo dos anos 1980 sua preocupação deslocou-se da patologia, distanciando-se dos conceitos de sacrifício, sofrimento e exigência, 
e se expandiu para a psicodinâmica do trabalho, passando a abarcar, para além de sofrimento, repressão e recalque, o prazer no trabalho, compreendendo-o como produtor de subjetividades e coletividades (p.39).

Nesse contexto, os debates passaram a discutir questões relativas à identidade, uma vez que, para Dejours, o trabalho é hoje o cenário mais importante para a realização do simesmo e da singularidade do sujeito, pois, para além da remuneração financeira, o trabalho seria responsável pela integração social e por recompensa simbólica, dando lugar à constituição do sujeito e a sua rede de significados (p.71). Mas, para permitir que o trabalho se constitua como produtor de subjetividades, seria necessário o desenvolvimento da confiança entre pares - e essa passou a circular como problemática central das pesquisas (capítulo 11). Segundo essa perspectiva, para retirar o trabalhador dos processos de excessiva individualização e de retração do social, do medo e do tédio - as maiores fontes de sofrimento patogênico no trabalho -, seria preciso o desenvolvimento de confiança mútua (capítulo 4). Só o desejo do trabalho conjunto e a busca de superação coletiva das contradições que resultam da própria organização do trabalho produziriam as bases da cooperação. O oposto disso seria um ato de bloqueio da produção do si-mesmo. É na busca de compreender o que produz as estratégias coletivas, a confiança mútua e o reconhecimento, como intervir diante do sofrimento e dos ruídos que ele manifesta no cotidiano do trabalho, seja por meio de acidentes, conflitos ou desmotivação, que as pesquisas ao longo do livro deixam ver a estrutura dos questionamentos, as buscas da etiologia, os métodos de intervenção (capítulo 2).

Na busca de condições para esse direcionamento, os autores dessa coletânea propõem uma escuta própria (p.88-92) e intervenções que pretendem provocar um processo de tomada de consciência dos silêncios, a constituição de um coletivo de regras que seja regido pela dimensão ética para o estabelecimento da confiança recíproca e para o fortalecimento da identidade pela via do reconhecimento das capacidades e sentimentos, com potencial para dar sentido ao trabalho e ao trabalhador (capítulos 3 e 8). Essa seria a condição de possibilidade da sublimação, isto é, da transformação da carga psíquica em criatividade e comprometimento com a qualidade - um trabalho, que ao ser feito, faz e transforma os sujeitos (Seligmann-Silva, 1994).

Desafiados pelos contínuos e velozes processos de mudança que ocorrem hoje do mundo do trabalho é que a apresentação das pesquisas e seus referenciais teórico-metodológicos se colocam como exigência de trabalho para outros pesquisadores, como meio de permitir aprimorar sua teorização e melhor compreender as estratégias defensivas erigidas pelos trabalhadores para suportar e mesmo superar o sofrimento psíquico (p.27).

Tratando-se de uma publicação que não apenas abriu novas perspectivas culturais para as organizações e seus trabalhadores, mas que também apresenta instrumentos teóricos e metodológicos desse conhecimento ainda em formação, o livro interessa não apenas àqueles que estudam e trabalham em torno da gestão propriamente dita - de pesquisadores e gestores a profissionais de recursos humanos -, mas é igualmente indispensável para todos aqueles que se interessam por questões que envolvem grupos, indivíduos e sociedade e que destacam como central o questionamento acerca de projetos de mudança. O que nos oferece a escola dejouriana é, em síntese, um convite para pensar uma realidade complexa, transdisciplinar, em um cotidiano em que o subjetivo e o trabalho ocupam, entrelaçados, um lugar central. 


\section{NOTA}

* Referência a Birman, 1999.

\section{REFERÊNCIAS}

BAUMAN, Zygmunt.

O mal-estar da pós-modernidade. Rio de Janeiro: Jorge Zahar. 1998.

BIRMAN, Joel.

Estilo de ser, maneira de padecer e de construir: sobre a histeria, a feminilidade e o

masoquismo. In: Birman, Joel. Cartografias do feminino. São Paulo: Editora 34. p.201-217. 1999.

CALDAS, Miguel Pinto; TONELLI, Maria José; LACOMBE, Beatriz.

Desenvolvimento histórico do RH no Brasil e no mundo. In: Boog, Gustavo; Boog,

Magdalena. Manual de gestão de pessoas e equipes. São Paulo: Gente. p.59-84. 2002.

DEBORD, Guy.

A sociedade do espetáculo: comentários sobre a sociedade do espetáculo. Rio de Janeiro: Contraponto. 1997.

DEJOURS, Christophe.

Uma nova visão do sofrimento humano nas organizações. In: Chanlat, Jean-François (Coord.). O indivíduo na organização: dimensões esquecidas. v.1.; 3.ed. Org. da ed. brasileira, Lanna Sette Torres. São Paulo: Atlas. p.149-174. 1996.

FISCHER, André L.

Um resgate conceitual e histórico dos modelos de gestão de pessoas. In: Fleury, M.T.L.

(Coord.). As pessoas na organização. São Paulo: Editora Gente. 2002.
HARVEY, David.

Condição pós-moderna: uma pesquisa sobre as origens da mudança cultural. São Paulo: Loyola. 1996.

HERNBERG, S.

Epidemiologia ocupacional: progressos e perspectivas. La medicina del Lavoro, Ed. América Latina, Milano, v.2, n.2, p.111-22. 1995.

LAURELl, Asa C.

Processo de trabalho e saúde. Revista Saúde em Debate, Londrina, n.11, p.8-22, 1981.

MOW.

Meaning of Work International Research Team. The meaning of working. London: Academic Press. 1987.

NAVARRO, Vicente.

Neoliberalism globalization, unemployment, inequalities, and the welfare state. International Journal of Health Services, Westport, v.28, n.4, p.607-82. 1998.

SELIGMANN-SILVA, Edith.

Da psicopatologia à psicodinâmica do trabalho: marcos de um percurso. In: Seligmann-Silva, Edith; Abdoucheli, Elisabeth; Jayet, Christian. Psicodinâmica do Trabalho. São Paulo: Atlas. p.13-20. 1994.

ZARIFAN, Philippe.

Objetivo competência: por uma nova lógica. Atlas: São Paulo. 2001. 